\author{
Abstracta Iranica \\ Abstracta Iranica Revue bibliographique pour le domaine irano-aryen \\ Volume 42-43 | 2021 \\ Comptes rendus des publications de 2019-2020
}

\title{
Reinhard Pirngruber. "Poverty and Inequality in First Millennium BCE Babylonia: Evidence from the Texts"
}

\section{Louise Quillien}

\section{(2) OpenEdition Journals}

Édition électronique

URL : https://journals.openedition.org/abstractairanica/52392

DOI : 10.4000/abstractairanica.52392

ISSN : 1961-960X

Éditeur :

CNRS (UMR 7528 Mondes iraniens et indiens), Éditions de l'IFRI

Référence électronique

Louise Quillien, « Reinhard Pirngruber. "Poverty and Inequality in First Millennium BCE Babylonia: Evidence from the Texts" ", Abstracta Iranica [En ligne], Volume 42-43| 2021, document 24, mis en ligne le 15 avril 2021, consulté le 20 décembre 2022. URL : http://journals.openedition.org/ abstractairanica/52392 ; DOI : https://doi.org/10.4000/abstractairanica.52392

Ce document a été généré automatiquement le 20 décembre 2022.

Tous droits réservés 


\title{
Reinhard Pirngruber. "Poverty and Inequality in First Millennium BCE Babylonia: Evidence from the Texts"
}

\author{
Louise Quillien
}

\section{RÉFÉRENCE}

Reinhard Pirngruber. "Poverty and Inequality in First Millennium BCE Babylonia: Evidence from the Texts" in R. Bußmann und T. Helms (eds.). Poverty and Inequality in Early Civilizations. (Studien zur Wirtschaftsarchäologie), Bonn: Habelt-Verlag, 2020, p. 39-47.

1 Les études récentes concernant l'histoire économique de la Babylonie sous l'empire néo-babylonien et les débuts de la domination achéménide ( $\mathrm{VI}^{\mathrm{e}}$ siècle av. J.-C.) ont montré que la région avait alors connu une phase de croissance économique. Dans cet article, est étudié l'impact de ce phénomène sur les niveaux de vie des catégories les plus pauvres et, plus largement, sur les inégalités sociales.

Dans un premier temps, l'auteur analyse brièvement les représentations sociales attachées à la pauvreté et le vocabulaire akkadien correspondant. Puis, il analyse et compare les niveaux de vie des deux catégories sociales les plus modestes: d'une part, les serfs des temples (širku), main d'œuvre dépendante rémunérée par des rations alimentaires et, d'autre part, les travailleurs libres et salariés, employés aux travaux agricoles et de construction. Le résultat montre que les širku vivaient en dessous du niveau de subsistance, tandis que la situation des travailleurs salariés était meilleure, juste au-dessus de ce niveau minimal.

Dans une dernière partie, l'auteur compare l'évolution des revenus de ces deux catégories sociales avec celle des revenus des notables urbains propriétaires de terres. L'étude, menée pour la seconde moitié du $\mathrm{VI}^{\mathrm{e}}$ siècle av. J.-C., période la mieux documentée, montre que le revenu des travailleurs salariés augmente davantage que 
celui des propriétaires. Cela signifie, selon l'auteur, que les inégalités de niveau de vie se sont réduites entre ces deux catégories sociales.

4 L'afflux d'argent issu du profit des conquêtes militaires aurait donc profité non seulement à une élite, mais aussi à une catégorie plus modeste de la population, à travers l'emploi de main d'œuvre salariée sur les grands chantiers de construction commandités par les rois. Le manque structurel de main d'œuvre en Babylonie a été favorable à ces travailleurs. Cependant, les serfs des temples širku sont exclus de cette dynamique.

5 L'article se termine par une comparaison intéressante avec Athènes à l'époque classique. Alors que les faibles inégalités sociales de la cité antique sont souvent expliquées par son modèle politique démocratique, l'exemple babylonien invite à prendre aussi en considération les éventuelles causes économiques de ce phénomène.

\section{AUTEURS}

\section{LOUISE QUILLIEN}

CNRS, UMR 7041, Arscan 